Consider the case of an able schoolboy who makes mathematics his chief study between the ages, say, of fifteen and nineteen; this period should suffice to give him a working knowledge of three-dimensional analysis, integral calculus and differential equations with their applications to the mechanics of solids, in addition to the subjects now required by the colleges, were it not for certain side issues which have arisen from the latter and assumed stupendous proportions. Foremost among these stands the excessive measure of attention given to the analysis of curves of the second degree. These form naturally a small section in a treatise on analytical geometry; yet while the far-reaching principles of the latter are lightly passed over, there is scarcely a method so abstruse or an artifice so petty that it may not give rise to a question in an entrance scholarship paper if its bearing be upon conic sections; so that no less than a third of a schoolboy's mathematical hours are frequently sacrificed to these curves. Their real interest is due, firstly, to their appearance in astronomy (the properties there required are few, and might be treated in the appendix of a text-book on dynamics), and, secondly, to their adaptability to treatment by pure geometry, the direct methods of which lend them an interest which is alien to every other branch of mathematics, and supply a mental discipline which is eisewhere unattainable. On this alone rests their title to rank as a separate subject.

But this, though the most aggravated, is not the only instance of the kind. The time spent on advanced trigonometry is out of all proportion to its practical or educational value ; the subject contains an introduction to the use of the complex quantity which properly forms part of the theory of functions, and includes a number of highly specialised problems which have no place in a syllabus so elementary as to exclude the integral calculus. A similar waste is caused by several large classes of questions, especially some on series, the ability to solve which implies nothing but an effort of memory, and by other fragments of high subjects which are thrust upon boys at an early stage and made artificially difficult by isolation from their proper context.

The above criticisms are not made in any spirit of hostility to examiners, who in framing their papers are trying to obviate the shortcomings of a system which is out of date and in need of radical reform. Five decades ago it was doubtless advisable, in view of the then state of school mathematics, to limit the entrance scholarship course to a few subjects, but under new and improved conditions is not an extension of syllabus preferable to the interweaving with these of a quantity of matter which, valuable as it may be to the problem setter, is for the student little else than a barrier to his progress?

But if the examinations in mathematics and science are to be brought into harmony, it is not only in the former that a new regime is needed. Under present conditions a boy could learn at school nearly the whole of the mathematics necessary for an advanced physical course. But to do this would jeopardise his chance of obtaining a first class in the science tripos unless. the authorities recognised the value of his mathematical training by a substantial equivalent of marks, so that he might make a mathematical entrance scholarship the preliminary to a science course. For those who have not a taste for theory it would still be possible to adopt an experimental regime from the outset, though it is questionable whether they could in the long run bear comparison with men who had cultivated a faculty which it is no exaggeration to call a sixth sense. The glory of Cambridge and her highest traditions are centred in the names of her mathematical physicists. But the environment which surrounded Maxwell and Kelvin no longer exists. And to-day the growth of subjects and the consequent tendency to specialisation have gone far to materialise the phantom barrier which separates the practical from the theoretical, and have laid on the authorities the burden of creating a new system which shall be capable of reproducing the giants of the past.

Dulwich College, March $\mathrm{I}_{3}$.

C. A. Rumsey.

The Morphology of Pleuronectidæ.

IN the Memoir on the Plaice by Messrs. Cole and Johnstone, reviewed in NATURE of March 20 (p. 459), there is a reference to Steenstrup's work on the metamorphosis of Pleuronectida which I think the reviewer would have done well to correct. The statement to which I refer is the following:- "This supposition (that the left eye passed through the substance of the head to reach the ocular side), absurd as it may seem to us now, was in fact believed by such an observer as Steenstrup."
The truth of the matter is that Steenstrup did not believe any supposition, absurd or otherwise, on the subject, but stated from actual observation that in certain larval Pleuronectidæe the eye of one side passed through the tissues of the head and emerged on the other side. The form in question was long known as Plagusia, and is now known to be the larva of Rhamboidichthys. The truth of Steenstrup's observations was fully confirmed by Alexander Agassiz at Newport, R.I.

On the other hand, in the "Story of Life in the Seas," by Prof. S. J. Hickson, it is stated that in the young of the soles the eye of one side passes through the head to the other side. This is equally incorrect.

Messrs. Cole and Johnstone also state that the Gadidæ are the nearest relatives of the Pleuronectidx, and promise to show that the morphological differences between the cod and the plaice, apart from the question of symmetry, are comparatively few and unimportant. I cannot find in the Memoir that they have redeemed this promise, and the morphological similarity of the two forms is contradicted by the authors themselves on $\mathrm{p}$. I85 of the Memoir. I believe it could be shown by proper investigation that the morphological differences between these two fish are numerous and profound.

I think some explanation was due from the reviewer concerning Dr. Woodward's "startling discovery" that in Cretaceous times Teleostei of the Clupeoid type had already translocated the pelvic fin into the jugular position. I have not yet had the pleasure of seeing Dr. Woodward's latest volume, but a Clupeoid with jugular fins seems to me indeed a startling discovery.

Penzance, March 22. J. T. Cunningham.

WhEN writing I was well aware that the sentence $\mathrm{Mr}$. Cunningham quotes was not happily construed, but seeing that comment (like that of $\mathrm{Mr}$. Cunningham himself) would needs be hypercritical, I allowed the matter to pass, in consideration of the context and of the desire to keep my review within bounds.

Concerning the Cretaceous teleostean described by Dr. Smith Woodward, I can only express my surprise that $\mathrm{Mr}$. Cunningham should be so neglectful of the current literature of his subjects as to be unaware of its occurrence. With the rest of his letter I have no concern.

The Writer of THE Review.

\section{Sun Pillars.}

I HAVE been deeply interested in the correspondence in NATURE bearing on the appearance of sun pillars, and particularly so in the communication of Prof. Johnstone Stoney (p. 465).

The display of March 6 mentioned by the Rev. Guy Bridges and Mr. W. A. Knight was not visible here; but a very noteworthy occurrence of the phenomenon took place here on December 3 last and another on January 7 last, and there was one feature common to both of these events which has not been mentioned as occurring in relation to those recorded by other observers, so far as I am aware, but which seems to me to be a prime factor in the causation of the phenomenon under consideration, and it is this :-Before, and after, the actual time of the setting of the sun, during my own observations, there was a strong display of cirrus cloud in the "true cirrus" form of paraliel bars, which appeared to run at right angles to the track of the setting sun, and roughly parallel, of course, to the horizon. As the setting sun neared the horizon, these bands of cloud became magnificently iridescent, displaying the spectrum colours of the rainbow, with the red nearest the horizon. As the sun set further the colours faded, beginning first at the red and following on in succession to the violet until this colour alone remained visible. Then ascended a beautiful pillar of a violet colour in exquisite shades, ascending gradually to a height of somewhere about twenty degrees above the horizon and then fading away slowly.

It seemed to me that the occurrence depended on $(a)$ the presence of cirrus cloud (ice spicula); (b) these clouds must be in a banded or striated form; $(c)$ they must lie at right angles to the track of the sun; and $(d)$ these clouds must, of course, be present in the immediate neighbourhood of the setting sun. There are, besides, certain atmospheric conditions which seem to be desiderated in order to favour opacity, as dryness of the air, with calmness in its movements, and, I believe, a comparatively high barometric pressure. At the time of my

NO. I692, VOL. 65] 